тер народной культуры, контактность с культурой других народов.

Следует учитывать, что возрождение традиционной культуры народов России, с одной стороны, должно сберечь духовное и материальное наследие, традиционные нравственные нормы, к сожалению, порядком утраченные, сохранить их как ядро культуры народов. С другой стороны, возрождение должно быть устремлено в информационную эпоху III тысячелетия. С этой точки зрения любая этническая культура должна постоянно впитывать новые достижения науки, образования, технологии, модернизироваться. Это означает, что возрождение культур тюркских и других народов России будет сплавом традиционного и нового, синтезом культурного ядра, оставленного нам предками. Это важный источник формирования духовных ориентиров общества, его нравственных ценностей.

\section{Evgeniya Takarakova,}

Ph.D in Cultural Studies, Expert on the culture of the Turkic peoples,

Center for the Culture of the Peoples of Russia,

Polenov State Russian House of Folk Art (Moscow),

cknr7@bk.ru

\section{Turkic ethics: tradition and modernity \\ (historical and cultural analysis)}

The article presents an analytical review of the reports and discussions at the All-Russian Round table «Turkic ethics: tradition and modernity» at the Polenov Center for the Culture of the Peoples of Russia (Moscow, November 12, 2020).

The Turkic peoples constitute the second largest ethnolinguistic group in the Russian Federation. Their geopolitical and multicultural space in Russia is a rich example of coexistence, cooperation and mutual enrichment of various ethnic phenomena. The revival of the cultures of the Turkic and other peoples is an important source of formation of spiritual guidelines and values of multinational Russia.

Keywords: Turkic peoples; ethics; Turkic ethics; tradition; multicultural space; Turks in Russia; intangible heritage.

\title{
Лейла Алмазова
}

\section{Этические концепции в трудах татарских мыслителей начала XX века}

В статье рассматриваются труды татарских богословов начала XX в. в контексте эволюции этических представлений татаро-мусульманского социума. В эпоху буржуазной трансформации на передний план выходят концепции свободы человеческой воли и ответственности, сменяющие веками формировавшиеся паттерны фатализма, неверия в собственные силы и возможности. Для обоснования собственной точки зрения татарские авторы пользуются классическими источниками - Кораном и Сунной пророка Мухаммада, находя в них достаточное количество цитат для убеждения слушателей в необходимости активной жизненной позиции, уверенности в себе, стремления к благополучию и земному процветанию. Данный подход коррелирует с описанным М. Вебером феноменом протестантской этики, способствовавшим, по его мнению, формированию буржуазного общества в Европе. Среди качеств, которые должны были выработать современники, Р. Фахретдинов (1959-1836), 3. Камали (1873-1942) и другие авторы называют отвагу, стойкость, непреклонность, оптимизм в сочетании с мудростью, верность данному слову, способствующие прогрессивному развитию личности и общества.

Ключевые слова: мусульманская этика; татарская богословская мысль; свобода воли ; предопределение; этические ценности; мораль буржуазного общества.

Алмазова Лейла Ильдусовна кандидат философских наук доцент кафедры востоковедения, африканистики и исламоведения, Институт международных отношений Казанский (Приволжский)

федеральный университет (Казань)

leila_almazova@mail.ru
Человеческие представления о различных аспектах бытия в том или ином обществе всегда зависят от контекста существования и меняются вместе с ним. Само понятие традиции в общественных дискуссиях используется как маркер идентичности и объединенной памяти, а не как четко определенное понимание содержания этой традиции. М. Хальбвакс, разработавший концепцию коллективной памяти, считал, что каждая группа формирует корпус того, что она будет помнить, а что считает нужным забыть [5]. 
В среде татар определяющей систему ценностей идеологией на протяжении тысячелетней истории был ислам, однако в рамках этой системы в разное время на первый план выходили самые разные концепции: от суфийской ориентации на загробное существование до идеалов воспитания активной творческой личности, сторонницы прогресса и процветания в земной жизни.

Начало XX века в истории татар связано с появлением феномена джадидизма (от араб. джадид - новый) широкого общественного движения за реформу традиционной мусульманской школы. Ему противостояла средневековая традиция, именуемая у татар «кадимзмом» (от араб. кадим - старый). В среде шакирдов студентов кадимистских (традиционалистских) медресе были широко распространены произведения Джамалетдина Бикташи «Фадаил аш-Шөһүр» [8, с. 436452], Сулеймана Бакыргани «Ахырзаман», «Бакырган китабы» [14, с. 70], Аллахияра Суфи «Субат ал-гажизин». Наряду с тем, что эти сочинения, за исключением первой книги, содержат ряд ценнейших философских идей в духе суфизма, их направленность на обесценивание мирского весьма ощутима. Часто встречаются призывы оставить все земные помыслы и устремиться к миру, который ждет человека за порогом смерти [7, с. 112].

Очевидно, что в период формирования буржуазного общества с его духом предпринимательства подобная ориентация отнюдь не способствовала прогрессу и процветанию мусульман. Поэтому реформаторы стремились кардинально изменить этические установки своих современников в сторону оптимизма и веры в собственные силы. М.Т. Степанянц отмечает, что реформаторская интерпретация онтологического аспекта концепции бога «дает основание для нового, соответствующего духу времени толкования проблемы места и роли человека в мироздании. Признание за ним определенной степени свободы воли не только оправдывает самостоятельность человеческих усилий, направленных на преобразование земной жизни, но возводит их в моральный, религиозный долг. Не мирская отрешенность, аскетизм, поиск индивидуального спасения, а активность, действенность в борьбе за переустройство общества на новых гуманистических началах являются главными этическими принципами религиозных реформаторов» [3, с. 106].

Позиции традиционализма были тем не менее еще сильны в татарском обществе, поэтому мыслители излагали свои новаторские идеи с определенной долей осторожности. Р. Фахретдин, в частности, стремясь не входить в противоречие с привычными установками ортодоксального ислама, так доказывал ценность земной жизни: «Загробная жизнь постигается путем покорности и поклонения, а покорность и поклонение неразрывно связаны с жизнью, и именно жизни присуща сила и энергия. Поэтому так как жизнь - это повод познать тот свет, то если я, чтобы достичь этой цели, буду любить жизнь - какой от этого будет вред?» [13, с. 470]. Ученый пытался сместить акцент с загробного существования на земное.

Одним из составляющих традиционного сознания было специфическое понятие «таваккул». Изначально это слово, понимавшееся как «решительность», «отвага», «надежда на исполнение», утратило свой истинный смысл и приобрело значение «упование». Р. Фахретдин выступает категорически против подобной трактовки, оправдывающей бездеятельность: «Уповать на провидение и тратить даром драгоценное время запрещено. Никто еще не видел, чтобы оттого, что никто ничего не делал, урожай был бы собран, а магазины наполнялись товарами. Жизнь - результат причинных связей». Для обличения бесперспективности этой по- 
зиции он приводит в пример пророка Мухаммада, который всего в своей жизни добивался трудом и активными действиями. Если бы упование заключалось только в вознесении молитв, то Пророк не рисковал бы своей жизнью на поле брани, а лишь молитвой вымаливал себе победу. Поэтому истинное упование на Аллаха заключается в том, чтобы со своей стороны выполнить все необходимые действия (тадбир), а уже потом возносить молитву о благополучном исходе предпринятых действий $[13$, с. 76$]$.

3. Камали, как и Р. Фахретдин, стремился рационализировать элементы мусульманского поклонения. В его четырехтомном сочинении «Философия ислама» две книги носят название «Философия поклонения». В них он подробно разбирает практическую пользу и внутренний смысл мусульманского культа. Например, среди полезных для человека элементов намаза - ежедневной пятикратной молитвы - он перечисляет следующие: человек в акте мольбы Аллаху переносится в высший мир и освобождается от тревог и мелочных забот; мольба приносит покой смятенной душе и врачует ее; гимнастика, совмещенная с духовным актом, одновременно способна помочь и душе, и телу; намаз учит терпению и методичности в жизни. Построение всех в ряд во время молитвы, невзирая на достоинства и заслуги, сбивает спесь и символизирует равенство людей перед Богом, союз и братство всего человечества. С точки зрения общественного блага общение в мечети учит интересоваться проблемами и нуждами единоверцев, помогать друг другу; наблюдение за большим количеством людей учит замечать положительные и отрицательные стороны членов махалли (мусульманской общины одного прихода), по возможности устранять в себе недостатки и приобретать достоинства [12, с. 55-59].
Зияэтдин Камали совсем не рассматривает мелкие детали отправления культа, как это было свойственно теологам традиционалистского толка, а обращает внимание на реальную нравственную, физиологическую, психологическую и духовную пользу мусульманских обрядов. Осуществив данный анализ, он разрушает устоявшуюся в мусульманском богословии идею, ведущую начало еще от ал-Ашари, о том, что человек не в силах постичь смысл актов поклонения, и поэтому должен лишь исполнять их и не спрашивать «зачем?».

3. Камали объясняет, что религия требует от человека исполнения нравственных и культовых предписаний не потому, что это угодно некому трансцендентному Богу, нет. Согласно его интерпретации, нравственно то, что служит процветанию и счастью человечества в целом и каждой личности в отдельности, а именно этим целям служит и все содержание истинной веры. То есть вера лишь следует за тем, что объективно прекрасно, а прекрасно то, что полезно для продолжения рода человеческого и обретения людьми совершенства. Осознание этого принципа, на котором должна строиться вера, «поможет человеку осознать себя истинным наместником Аллаха на земле и, с одной стороны, благодаря разуму, а с другой - благодаря религии, которая, как луч, освещает доселе скрытое, обрести понимание законов Вселенной, предвидения последствий своих поступков и достичь счастья - истинной цели ислама» [11, с. 139].

Переходя к изложению самого главного Божественного закона, 3. Камали начинает с обоснования следующего тезиса: успех и земное благополучие - это знак свыше о том, что человек или целое сообщество людей движутся в правильном направлении: «Некоторые государства оканчивают свои дни, и их имена остаются 
лишь в истории... а некоторые нации растут, берут под свое покровительство новые земли, другие же пребывают в изоляции, некоторые правят всем миром, слава других близится к закату, одни становятся богатыми владельцами миллионов, а некоторые испытывают лишения... Причина всего этого в жизни в соответствии со знанием божественных причин или в жизни без подобного соответствия» [11, с. 302]. В известном смысле этот вывод развивает и рационализирует идеи протестантизма. Макс Вебер объяснял успехи европейской цивилизации Нового времени сдвигом в общественном сознании масс, произошедшем в результате христианской Реформации, когда успех человека в его земной жизни признавался свидетельством его богоугодности и богоизбранности. То есть решение проблемы предопределения осуществляется в ключе его жизненного успеха или неудачи. Согласно теории Вебера, этот принцип лег в основу процветания западной цивилизации.

Если проблема богоизбранности решалась во времена христианской Реформации сугубо метафизически и иррационально, то несколько веков спустя татарские реформаторы пытаются заключить тот же принцип в строго логические рамки. Успех человека в его деятельности связывается ими с соответствием его действий божественным законам. Они считают, что и обществу в целом, и отдельному человеку неизбежно будет сопутствовать удача в том случае, если он строит свою жизнь на основе ее соответствия законам природы, изначально установленным Аллахом.

Мусульманский мир к началу ХХ в. переживал нелегкие времена. Вынужденная конкуренция с самыми развитыми странами обнажала слабые стороны традиционных обществ. В чем же состояла ошибка мусульман, заведшая их в экономический, а главное, в духовный тупик во времена позднего ислама? По мнению мусуль- манских реформаторов, один из самых существенных просчетов заключался в этике пассивности, вызванной неверным толкованием проблемы предопределения. Поэтому их главной задачей стало убедить современников в необходимости активного отношения к жизни, оптимизма, стремления к достижению более высокого уровня жизни, что должно привести к главной цели развитию духовности и знаний.

Эти идеи витали в воздухе, однако логическую и концептуальную завершенность они приобрели в трудах Зияэтдина Камали. Именно он стал наиболее последовательным создателем принципиально новой концепции свободы воли, а также проблемы теодицеи [9]. Он писал, что почти каждый век мусульмане заново задаются вопросом: как совместить то предание, что Аллах все, что есть, и все, что будет, записал на вечной скрижали, и «чернила уже высохли», с тем, что, несмотря на это, человек обязан отвечать за свои дела перед Всевышним? 3. Камали очень образно сравнил это противоречие с тем, как если бы некто, приготовив ядовитый отвар, дал выпить его человеку. После того как тот осушил чашу, этот некто стал бы кричать: «Зачем выпил? Не пей!». Подобным образом философ утрировал абсурдность ситуации, дабы опровергнуть идеи фатализма, столь присущие некоторым кругам религиозных деятелей своего времени. Высказывание об уже высохших чернилах на вечной скрижали философ толковал весьма оригинально. Он утверждал, что на ней записана вовсе не судьба человека, а «лишь вечный Божественный Закон, гласящий, что человек волен выбирать между своей верой и безверием, счастьем и бедой, добром и злом и получить за этот выбор то, что он благодаря ему сам заслужил» [11, с. 317].

Философ считал, что человек обладает правом выбора: «В соответствии с исламской верой, человечество 
было создано свободным. Подобно тому, как во всех других делах, человек свободен и в вопросах совести и веры. Если человек хочет, может питаться неверием, если хочет, может быть и правоверным, ему дана в этом свобода... Счастье каждого человека зависит от его ремесла и усердия - такой заложен всеобщий закон» $[11$, c. 318$]$.

Процветание, прогресс и богатство - это показатель соответствия жизни людей познанному божественному закону, изложенному в доступной форме во всех трех мировых религиях. Признавая право всех монотеистических религий на истину, мусульманские реформаторы и обновители не сомневались в том, что наиболее полно и совершенно истина изложена в исламе. В то же время зло - болезни, бедность, нищета - рассматривается как знак нарушения человеком божественного порядка: «В мире истинного зла нет; если нам и видны различные виды зла, то тот смысл, который в нем заложен, свидетельствует лишь о милости Аллаха. Поистине Аллах Знающий Мудрый» [11, с. 328]. Согласно данным представлениям, все возникающие проблемы социума или индивидуума являются следствием его собственных ошибок в прошлом.

Аллах, по мнению Камали, в вопросе предопределения играет роль закона справедливости, как у мутазилитов, и сам не вмешивается, по крайней мере в этом мире, в дела людей. Его присутствие ощущается лишь опосредованно - благодаря снизошедшим из Божественного источника религиям. Именно тем, что к людям регулярно посылались пророки, и обусловливается забота Всевышнего о человечестве. Поэтому человек, зная об этом, сам творит свою судьбу.

Совершенно особо для татар стоял вопрос об отношении к бедности и богатству. Этика традиционализма проповедовала идеи, согласно которым нищенство счи- талось чуть ли не заслугой человека: «ал-факр фахри» [6, с. 123] (бедность почетна). В то же время пропаганда философии бедности была достаточно опасна для общества. Специфика татарского социума заключалась в том, что финансировала всю систему мусульманского образования махалля, очевидно, что большую часть средств предоставляли наиболее богатые члены. Успех просветительской деятельности самих мусульманских реформаторов (были ли они редакторами газет и журналов, как Р. Фахретдин или А.-Х. Максуди, или возглавляли медресе, как Х.-Г. Габаши или 3. Камали) напрямую зависел от щедрости меценатов и их количественного соотношения в обществе. Вопрос для татар стоял следующим образом: или прогресс, богатство и процветание мусульман и как следствие распространение знаний и образования, или бедность, нищета и упадок культуры и духовности общества. Поэтому реформаторы стремились всеми способами поощрять такие качества, как предприимчивость и умение зарабатывать деньги. Для доказательства желательности материального достатка для мусульманина они апеллировали к основам мусульманского вероучения.

Закят - один из столпов ислама - одна сороковая часть движимого имущества, которую мусульмане ежегодно выплачивают на нужды общины. Как правило, деньги передаются в мечеть, а дальше распределяются в соответствии с потребностями нуждающихся. Определенную сумму обязан выплачивать каждый мусульманин, однако в том случае, если он сам должник, выплата закята не считается дозволенной. С этой позиции бедность препятствует выполнению одного из самых важных предписаний ислама $[10$, с. 10$]$. Кроме того, ислам предписывает оказывать мусульманам благодеяния, а отсутствие материальных средств лишает верующего возможности совершения этого богоугодного дела. 
Таким образом, прежний еще библейский тезис о том, что «легче верблюд пролезет в игольное ушко, чем богатый попадет в рай», заменяется обоснованием необходимости приумножения богатства с целью использования его на благо общества. Здесь опять же просматривается несомненное сходство с этикой протестантизма, где «желание быть бедным было бы равносильно желанию быть больным и достойно осуждения $<\ldots>$ нищенство <...> это не только грех бездеятельности, но и нарушение завета любить ближнего своего» [2, c. 191].

Татарские реформаторы считали, что немаловажную роль в достижении материального благополучия играет расчетливость и экономность. Этот тезис вполне сравним с той особенностью протестантской этики, что проповедовала вариант мирского аскетизма, внешне преследовавшего чисто накопительские цели. Помимо обоснования почетности стремления к материальному благополучию, реформаторы разработали некий комплекс личных качеств, необходимых татарам для более динамичного развития в русле мировых процессов. Особая роль в разработке нравственных ориентиров для современников принадлежит Ризаэтдину Фахретдину. Он полагал, что в жизни каждого народа в зависимости от времени может наблюдаться избыток одних качеств, а также недостаток других. При этом задача состоит в том, чтобы привести все это в такое равновесие, при котором мусульманская умма сможет гармонично развиваться.

В результате глубоких размышлений философ пришел к выводу, что самое главное, что мешает татарам, недостаток веры в собственные силы. Он писал про своих соплеменников, что они в своей массе привыкли верить в отцов-дедов, благословения и молитвы, в силу помощи умерших и святых, а в тех случаях, когда требу- ется найти выход из какой-либо сложной жизненной ситуации, люди, вместо того чтобы смело взяться за дело, бегут к могилам святых или обращаются за помощью к шейхам и ишанам. «Это явное свидетельство неверия в собственные силы. Причем беда заключается еще и в том, что по наследству это переходит и к молодежи, она несамостоятельна и постоянно ждет помощи со стороны. В то же время в развитых странах люди чрезвычайно уверенны в себе, хотя ни по уму, ни по таланту ничем от нас не отличаются. Именно это является залогом их успеха. Человек, верящий в собственные силы, в случае препятствий на его пути не станет предаваться отчаянию, а просто приложит все усилия, чтобы преодолеть их» [13, с. 415]. Р. Фахретдин годами исследовал биографии великих людей и пришел к выводу, что их определяющим качеством была безусловная вера в собственные силы.

Кроме оптимизма и уверенности в себе, среди других качеств, более всего недостающих татарам, философ называл верность. Мыслитель выделял несколько ее типов. Первый - верность в словах, то есть человек всегда должен говорить правду о том, что он думает и исповедует. Р. Фахретдин считал, что многие неудачи татар происходят оттого, что они под видом благообразия и почтения, а чаще, просто из страха, научились скрывать свои истинные мысли и перестали говорить правду. Если во времена сподвижников Пророка каждый мог высказаться с критикой в адрес любого, то позже различного рода начальники и правители приучили мусульман скрывать свое мнение, а народ, чей разум скован страхом, не может раскрыть свой потенциал в полной мере. Второй тип верности - честность во взаимоотношениях. Тут имеется в виду соблюдение правил в торговле, возвращение долгов и вещей, сданных на хранение. И в последнюю очередь, но не по зна- 
чению, Фахретдин упоминал о верности данным обещаниям [13, с. 137]. В трактовке верности Р. Фахретдин в большей степени обращал внимание на формирование у современников качеств, необходимых в сфере деловой этики.

Р. Фахретдин также считал, что татарам недостает отваги, стойкости и непреклонности. Вспоминая великих деятелей прошлого - Абу Ханифу, Ибн Ханбала, Ибн Рушда и многих других, он писал, что они никогда не прославились бы, не обладая этими свойствами характера. Философ с сожалением отмечал, что в последнее время мусульмане не могут похвастаться своими столь же прославленными учеными или какими-либо гениальными изобретениями: «Ведь все новые достижения - пароход, железная дорога, телефон, телеграф придуманы не нами. В то время как человек пришел на эту землю, чтобы двигаться вперед, мы стоим на месте» [13, с. 138]. Чтобы общество не испытывало недостатка в профессионалах, философ считает необходимым каждому уже с детства определять свое предназначение в жизни и прилагать все усилия для достижения своей основной цели.

Р. Фахретдин призывал современникам наряду с отвагой, стойкостью и непреклонностью к оптимизму в сочетании с мудростью. Ибо тот, чей дух постоянно пребывает в печали и безнадежности, не способен выигрывать в битве жизни. Для достижения мирского счастья недостаточно лишь ждать, когда оно само к тебе придет: «Порой приходится преодолевать моря и горы, пробиваться сквозь бури» [13, с. 417], но стойкий человек, вооружившись всеми этими качествами, без сомнения сможет завоевать себе место под солнцем.

Идеи татарских ученых в области этики удивительно актуальны в наши дни. Автору видится несомненное сходство их концепций с современными психологиче- скими теориями. Негативное сознание, восприятие жизни как тяжкого бремени приводит к тому, что человеческое существование действительно превращается в невыносимые страдания. И наоборот, усвоение паттернов успеха, веры в собственные силы, решительности способно влиять на исполнение самых невероятных проектов и реально улучшать жизнь людей $[4$, c. 103].

Идеи татарских реформаторов связывались с этническим историко-культурным наследием и основывались на значительном фундаменте, состоящем из богатейшего комплекса этических понятий, разработанных в средневековой мусульманской литературе адаба. Татарские ученые перенимали, в частности, представления ал-Газали о противоборстве в человеке многочисленных душ - души шайтана, животной, человеческой, ангельской и божественной, от победы той или иной из которых зависит общая доминанта человеческого характера. Еще одна идея, впервые заявленная еще Аристотелем в «Никомаховой этике», о добродетели как середине, зажатой между двумя пороками, прошедшая через наследие многих исламских мыслителей, нашла свое прочтение и у татарских реформаторов. Использование хадисов и примеров из биографии пророка Мухаммада, как иллюстрации добродетельного поведения, - все это было вновь востребовано в наследии татарских ученых.

Очевидно, однако, что указанные традиции дополнились существенным переосмыслением этико-философских оснований, выразившихся в решении проблем предопределения, добра и зла. Рационализация в истолковании этих бывших долгое время сугубо эзотерическими проблем способствовала процессам освобождения личности и создания на этой основе подлинно открытого и самодостаточного общества. 


\section{Лumepamypa:}

1. Аль-Газали А. Эликсир счастья. Казань: Иман, 1998. 16 с

2. Вебер М. Протестантская этика и дух капитализма // Вебер М. Избранные произведения. М.: Прогресс, 1990. 808 с.

3. Степанянц M.T. Философия зарубежного Востока XX века // История восточной философии: Учебное пособие / Ред. М.Т. Степанянц. М.: ИФРАН, 1998. С. 100-120.

4. Тойч Дж.М., Тойч Ч.К. Второе рождение или искусство познать себя. Уфа: Санрей, 1997. 183 c.

5. Halbwachs M. On Collective Memory. Chicago: Chicago University Press, 1992. 254 p.

6. Аллаһияр С. Собәтел-гажизин. Казан: Иман, 2000. 64 б.

7. Бакырган китабы: XII-XVIII йөз төрки-татар шагыйрьләре әсәрләре / Текстларны басма өчен Ф.Яхин әзерләде. Казан: Татар. кит. нәшр., 2000. 2396.

8. Ибрагимова Ф. Балалар әдәбияты // Татар әдәбияты тарихы. Т.6. Казан: Татар. кит. нәшр., 1985. 436-452 б.

9. Камали 3. Аллаһ гадәләте. Уфа: Шарыкъ матбагасы, 1911. 56 б.

10. Камали 3. Дини тәдбирләр. Уфа: Шарыкъ матбагасы, 1913. Б. 10

11. Камали 3. Фәлсәфәи исламиядән 1 кисәк: Фәлсәфәи игътикадия. Уфа: Шарыкъ матбагасы, 1911. 330 с.

12. Камали 3. Фәлсәфәи исламиядән. 2 кисәк: Фәлсәфәи гыйбадәт. Уфа: Шарыкъ матбагасы, 1909. 216 с.

13. Фәхретдин Р. Жәвамигуль кәлим шәрхе. Казан: Иман, 1995. 6026.

14. Яхин Ф. Татар шигъриятенда дини мистика хэм мифология. Казан: ТДгИ, 2000. 266 c.

\section{Leyla Almazova}

Ph.D in Philosophy, Associate Professor, Department of Oriental, African and Islamic Studies, Institute of International Relations, Kazan (Volga Region) Federal University (Kazan),

leila_almazova@mail.ru

\section{Ethical concepts in the works of Tatar thinkers \\ of the early 20 th century}

The article examines the Tatar theologians' works of the early 20th century in the context of the evolution in the ethical ideas of the Tatar-Muslim society. In the era of bourgeois transformation, the concepts of human free will and responsibility come to the fore, replacing the patterns of fatalism, disbelief in one's own strength and capabilities that have been formed for centuries. To substantiate their own point of view, Tatar authors use classical sources - the Koran and the Sunnah of the Prophet Muhammad, finding in them a sufficient number of quotations to convince listeners of the need for an active life position, self-confidence, desire for well-being and earthly prosperity. This approach correlates with the phenomenon of Protestant ethics described by M. Weber, which, in his opinion contributed to the formation of bourgeois society in Europe. R. Fahrettinov (1959-1836), Z. Kamali (1873-1942), and other authors call courage, fortitude, inflexibility, optimism combined with wisdom, and loyalty to one's word as qualities that should have been cultivated by contemporaries, contributing to the progressive development of individuals and society.

Keywords: Muslim ethics; Tatar theological thought; free will; predestination; ethical values; morality of bourgeois society.

\section{Лариса Анжиганова}

\section{Онтологизация этики в традиционном мировоззрении хакасов}

В статье рассмотрены основные аспекты онтологизации этики в традиционном мировоззрении этноса (космоцентрические, социоцентрические, эгоцентрические). На материалах хакасского фольклора показано, что нормы морали возникли в процессе одновременного сотворения природы, общества и человека, и именно поэтому они носят онтологический и экологический характер. Сохранение целостности, благополучия и полноты рода и народа в целом - зона ответственности каждого человека, залог его вечной жизни. Для традичионного мировоззрения хакасов особую ченностью представляла не столько индивидуальная жизнь, сколько коллективная чель - сохранение гармонии и полноты бытия. Это возможно при сохранении человеком чистоть мысли, чувства, слова, поступка. Строгая упорядоченность общества препятствовала проявлениям экзистенциального вакуума: человек в традиционном обществе обладал позитивным мировоззрением, что способствовало позитивной деятельности, ориентированной на творчество.

Исследование осуществлено в рамках проекта РФФИ №19-011-00365 «Проблемы эффективного использования человеческого капитала: региональное измерение».

Ключевые слова: хакасы; онтологизация этики; космоцентризм; социоцентризм; духовное наследие; род у хакасов.

Сегодня, когда крайне обострены взаимоотношения природа - человек, общество - человек, когда сам человек ищет смыслы собственного бытия в радикально изменившихся обстоятельствах, неизбежно возникают вопросы, связанные с этическим аспектами мировоззрения. Мы вынуждены констатировать печальные 